\title{
ANALISIS FAKTOR PENENTU KEINGINAN PEGAWAI UNTUK BERHENTI BEKERJA DAN IMPLIKASINYA PADA PERBANKAN SYARIAH DI INDONESIA.
}

\author{
Boby Rachman Gumay, Achmad Firdaus, Mukhamad Yasid \\ Institut Agama Islam Tazkia, Bogor \\ Jalan Ir. H. Djuanda No. 78 Sentul City, Bogor 16810 Indonesia \\ bobygumay@gmail.com
}

\begin{abstract}
This study aims to analyze the effect of work environment, compensation and religiosity on turnover intention of Islamic Banking employees in Indonesia. The questionnaire was filled out by 209 employees of Islamic banks in Indonesia and the data obtained was processed using Structural Equation Modeling (SEM) method with SmartPLS software version 3.2. Work environment and compensation negatively affect turnover intention. Religiosity is the only variable that positively influences turnover intention. This paper is one of the pioneer research in the field of Human Resource Development (HRD) focusing on the matter of turnover intention which combining three independent variables (work environment, compensation and religiosity) with at least $50 \%$ Islamic Banks in Indonesia took place as samples. This research is expected to benefitting management in Islamic banking so they could establish proper strategic policy in the field of employment, especially those related to turnover intention to control employee turnover rate in order to improve the performance of Islamic banking in Indonesia in the future.
\end{abstract}

Keywords: Work Environment, Compensation, Religiosity, Turnover Intention, Islamic Banking

\begin{abstract}
Abstrak
Penelitian ini bertujuan untuk menganalisa pengaruh lingkungan kerja, kompensasi dan religiusitas terhadap keinginan pegawai untuk berhenti bekerja pada perbankan syariah di Indonesia. Kuesioner diisi oleh 209 orang pegawai bank syariah di Indonesia dan data yang diperoleh diolah dengan metode Structural Equation Modeling (SEM) menggunakan software SmartPLS versi 3.2. Lingkungan kerja dan kompensasi berpengaruh negatif terhadap keinginan pegawai untuk berhenti bekerja. Religiusitas adalah satu-satunya variabel yang berpengaruh positif terhadap keinginan pegawai untuk berhenti bekerja dari perbankan syariah. Penelitian ini merupakan salah satu penelitian perintis di bidang personalia (HRD) yang membahas mengenai keinginan pegawai untuk berhenti bekerja dengan menggabungkan tiga variabel independen yakni lingkungan kerja, kompensasi dan religiusitas dengan sampel serta mencakup $\pm 50 \%$ entitas bank syariah yang ada di Indonesia. Penelitian ini diharapkan dapat memberikan manfaat bagi manajemen di perbankan syariah agar dapat mengambil langkah stratejik yang tepat di bidang kepegawaian terutama yang berkaitan dengan keinginan pegawai untuk berhenti bekerja sehingga dapat mengatasi tingkat keluarnya pegawai yang tinggi demi meningkatkan kinerja perbankan syariah di Indonesia secara umum di masa mendatang.
\end{abstract}

Kata Kunci : Lingkungan Kerja, Kompensasi, Religiusitas, Keinginan Pegawai untuk Berhenti Bekerja, Perbankan Syariah

\section{Pendahuluan}

Sumber Daya Manusia (SDM) merupakan sumber daya yang penting bagi suatu organisasi maupun perusahaan (Altman, 2009). Fungsi manusia sebagai sumber daya dapat disamakan dengan sumber daya lain di sebuah perusahaan, baik sumber daya alam, modal, maupun teknologi (Becker \& Gerhart 1996). Fungsi manusia sebagai sumber daya urgensinya lebih penting dari seluruh sumber daya di atas, karena manusialah yang dapat memanfaatkan seluruh sumber daya tersebut. Tanpa adanya manusia, seluruh sumber daya di atas menjadi siasia.

Perusahaan membutuhkan pegawai yang terlatih dan kompeten di bidangnya untuk menjalankan fungsinya di bagian masing-masing. Namun, pegawai yang kompeten tentunya memiliki daya tarik tersendiri bagi perusahaan lain di bursa tenaga kerja, sehingga kesempatannya untuk mencari pekerjaan lain pun terbuka lebar (Gillingham dalam Samuel \& Chipunza, 2009). Meretensi pegawai (mencegah pegawai keluar dari perusahaan) adalah salah satu tantangan terbesar 
yang dihadapi oleh Manajemen Sumber Daya Manusia dewasa ini. Fluktuasi ekonomi dan persaingan bisnis membuat perusahaan terus berusaha untuk meretensi pegawai-pegawai terbaiknya agar tidak berpindah ke perusahaan lain, walaupun dengan membayar harga yang tinggi. Karena mencari pengganti seseorang dengan kemampuan yang setara (dengan yang meninggalkan perusahaan) bukanlah tugas yang mudah bagi para perekrut pegawai (Punia \& Sharma, 2008).

Diantara hal-hal yang menjadi dampak dari keluarnya pegawai adalah menurunnya kualitas pelayanan yang diberikan oleh perusahaan, sehingga dapat mempengaruhi kepuasaan pelanggan/customer, disamping perusahaan juga harus mengeluarkan biaya yang tidak sedikit untuk mencari pengganti bagi pegawai yang keluar tersebut (Abbasi \& Hollman, 2000). Dalam industri perbankan, tingkat perputaran pegawai sangatlah tinggi hingga dapat mencapai $50 \%$ tiap tahunnya (Lee \& Mowday, 1987). Contoh lain, tingginya perpindahan pegawai di Uni Emirat Arab mencapai angka $21 \%$ dan menimbulkan kerugian senilai 9,9 milyar Dirham Uni Emirat Arab atau setara 2,7 milyar USD pertahunnya (Suliman \& Al-Obaidli, 2011). Sebagai gambaran, berikut adalah data jumlah pegawai yang keluar dari salah satu Bank Umum Syariah di Indonesia pada periode tahun 2016-2018:

Tabel 1

Data Pegawai Bank Syariah X

\begin{tabular}{lccc}
\hline Tahun & 2016 & 2017 & 2018 \\
\hline Jumlah & 2307 & 1431 & 1281 \\
Pegawai & & & \\
Masuk & 286 & 312 & 291 \\
Keluar & 1162 & 462 & 399 \\
Akhir & 1431 & 1281 & 1173 \\
Periode & & & \\
\hline
\end{tabular}

Berdasarkan data di atas, dapat diketahui selama tiga tahun tersebut di Bank Syariah X terjadi fenomena turnover pegawai yang cukup tinggi, dimana pegawai yang keluar lebih banyak daripada pegawai yang masuk dan hal ini dapat berpotensi buruk kepada usaha Bank Syariah X, terlebih jika hal ini turut terjadi pula di bank syariah yang lain.

\section{Metode Penelitian}

\section{Desain Penelitian}

Penelitian ini dilakukan dengan mengumpulkan data dari pegawai yang bekerja di bank-bank syariah yang ada di Indonesia. Data yang didapat kemudian dianalisa dengan metode
Structural Equation Modeling (SEM) menggunakan software SmartPLS versi 3.2.

\section{Populasi dan Responden Penelitian (Sampling)}

Populasi dalam penelitian ini adalah seluruh pegawai di perbankan syariah di Indonesia. Sementara, sampel yang dipilih dari populasi adalah pegawai dengan masa kerja minimal satu tahun kalender di banknya. Hal ini bertujuan agar sampel dalam penelitian ini adalah pegawai yang telah memiliki pengalaman kerja yang cukup dan telah merasakan dinamika pekerjaan sebagai seorang pegawai di perbankan syariah, sehingga dapat memberikan respon yang representatif dalam menjawab kuesioner yang diberikan. Nama-nama institusi yang pegawainya menjadi sampel dalam penelitian ini dirahasiakan, agar tidak mencederai reputasi bank yang bersangkutan.

Untuk jumlah sampel, Hair et al. (2014) menyatakan bahwa apabila dalam sebuah penelitian terdapat $\leq 5$ variabel, maka jumlah sampel minimalnya adalah 100 orang. Dalam penelitian ini, terdapat 209 orang yang memenuhi syarat sebagai responden. Berikut adalah deskripsi responden penelitian ini:

Tabel 2

Deskripsi Responden Berdasarkan Jenis Kelamin

\begin{tabular}{lcc}
\hline \multicolumn{1}{c}{$\begin{array}{c}\text { Jenis } \\
\text { Kelamin }\end{array}$} & Jumlah & Presentase \\
\hline Laki-laki & 123 & $58,89 \%$ \\
Perempuan & 86 & $41,11 \%$ \\
\hline Total & 209 & $100 \%$ \\
\hline
\end{tabular}

Tabel 3

Deskripsi Responden Berdasarkan Usia

\begin{tabular}{lcc}
\hline \multicolumn{1}{c}{ Usia } & Jumlah & Presentasi \\
\hline 20-29 tahun & 67 & $32,06 \%$ \\
30-39 tahun & 96 & $45,93 \%$ \\
40-49 tahun & 35 & $16,75 \%$ \\
50-59 tahun & 10 & $4,78 \%$ \\
60 tahun ke & 1 & $0,48 \%$ \\
atas & & \\
\hline Total & 209 & $100 \%$ \\
\hline
\end{tabular}

Tabel 4

Deskripsi Responden Berdasarkan Status Pernikahan

\begin{tabular}{lcc}
\multicolumn{1}{c}{$\begin{array}{c}\text { Status } \\
\text { Pernikahan }\end{array}$} & Jumlah & Presentase \\
\hline Menikah & 168 & $80,38 \%$ \\
Tidak & 41 & $19,62 \%$ \\
Menikah & & \\
\hline Total & 209 & $100 \%$ \\
\hline
\end{tabular}


Tabel 5

Deskripsi Responden Berdasarkan Tingkat Pendidikan Terakhir

\begin{tabular}{lcc}
\hline \multicolumn{1}{c}{ Tingkat } & Jumlah & Presentase \\
Pendidikan & & \\
\hline SMA & 2 & $0,96 \%$ \\
D3 & 5 & $2,39 \%$ \\
S1 & 171 & $81,82 \%$ \\
S2 & 30 & $14,35 \%$ \\
S3 & 1 & $0,48 \%$ \\
\hline Total & 209 & $100 \%$ \\
\hline
\end{tabular}

Tabel 6

Deskripsi Responden Berdasarkan Domisili

\begin{tabular}{lcc}
\hline \multicolumn{1}{c}{ Domisili } & Jumlah & Presentase \\
\hline Jabodetabek & 148 & $70,81 \%$ \\
Banten & 2 & $0,96 \%$ \\
Jawa Barat & 16 & $7,66 \%$ \\
Jawa Tengah & 7 & $3,35 \%$ \\
Jawa Timur & 12 & $5,74 \%$ \\
Sumatera & 19 & $9,09 \%$ \\
Mataram & 2 & $0,96 \%$ \\
Sulawesi & 3 & $1,44 \%$ \\
\hline Total & 209 & $100 \%$ \\
\hline
\end{tabular}

Tabel 7

Deskripsi Responden Berdasarkan Tempat Bekerja

\begin{tabular}{lcc}
\hline Tempat Bekerja & Jumlah & Presentase \\
\hline Bank Sy ariah A & 77 & $36,84 \%$ \\
Bank Sy ariah B & 39 & $18,66 \%$ \\
Bank Sy ariah C & 29 & $13,88 \%$ \\
Bank Sy ariah D & 28 & $13,40 \%$ \\
Bank Sy ariah E & 13 & $6,22 \%$ \\
Bank Sy ariah F & 11 & $5,26 \%$ \\
BPRS & 4 & $1,91 \%$ \\
Bank Sy ariah G & 3 & $1,44 \%$ \\
Bank Sy ariah H & 2 & $0,96 \%$ \\
Bank Sy ariah I & 2 & $0,96 \%$ \\
Bank Sy ariah J & 1 & $0,48 \%$ \\
\hline Total & 209 & $100 \%$ \\
\hline
\end{tabular}

Tabel 8

Deskripsi Responden Berdasarkan Level Jabatan

\begin{tabular}{lcc}
\hline \multicolumn{1}{c}{ Jabatan } & Jumlah & Presentasi \\
\hline Staff & 118 & $56,46 \%$ \\
$\begin{array}{l}\text { Supervisor/Unit } \\
\text { Head }\end{array}$ & 46 & $22.01 \%$ \\
Kepaa & & $18,66 \%$ \\
$\begin{array}{l}\text { Bagian/Dept. } \\
\text { Head }\end{array}$ & 39 & \\
$\begin{array}{l}\text { General } \\
\text { Manager/Group }\end{array}$ & 3 & $1,44 \%$ \\
Head & & \\
Direksi/Komisaris & 3 & $1,44 \%$ \\
\hline Total & 209 & $100 \%$ \\
\hline
\end{tabular}

\section{Kuesioner}

Penelitian ini dilakukan dengan menyebarkan kuesioner yang terdiri dari 34 pertanyaan. Pertanyaan-pertanyaan dalam kuesioner ini disusun oleh peneliti dan sebagiannya diambil dari beberapa penelitian terdahulu, diantaranya adalah penelitian milik Raziq and Maulabakhsh (2015) mengenai lingkungan kerja, kemudian Misra et al. (2013) mengenai kompensasi, Abu-Raiya et al. (2008) dan Ramlan (2017) mengenai religiusitas dan Al-Hummadi (2013) mengenai keinginan pegawai untuk berhenti bekerja. Jawaban dalam penelitian ini diukur menggunakan skala-likert 1-5, dengan bobot jawaban sebagai berikut: $1=$ sangat tidak setuju, $2=$ tidak setuju, $3=$ ragu-ragu, $4=$ setuju, $5=$ sangat setuju.

\section{Hasil dan Pembahasan \\ Validity Test}

Pertama-tama, dilakukan validity test untuk mengukur konsistensi dan kelayakan jawaban dari pertanyaan-pertanyaan yang diberikan di dalam kuesioner, dengan mengukur nilai Cronbach's Alpha, Composite Reliability dan Average Variance Extracted (AVE). Hasilnya adalah sebagai berikut:

Tabel 9

Validity Test

\begin{tabular}{lccc}
\hline \multicolumn{1}{c}{ Variabel } & $\begin{array}{c}\text { Croncachs } \\
\text { Alpha }\end{array}$ & $\begin{array}{c}\text { Composite } \\
\text { Reliability }\end{array}$ & AVE \\
\hline $\begin{array}{l}\text { Lingkungan } \\
\text { Kerja (X1) }\end{array}$ & 0,893 & 0,913 & 0,513 \\
$\begin{array}{l}\text { Kompensasi } \\
\text { (X2) }\end{array}$ & 0,942 & 0,953 & 0,744 \\
$\begin{array}{l}\text { Religiusitas } \\
\text { (X3) }\end{array}$ & 0,933 & 0,938 & 0,507 \\
$\begin{array}{l}\text { Keinginan } \\
\text { Pegawai }\end{array}$ & 0,914 & 0,940 & 0,795 \\
untuk & & & \\
$\begin{array}{l}\text { Berhenti } \\
\text { Bekerja (Y) }\end{array}$ & & & \\
\hline
\end{tabular}

Dari hasil di atas, didapati bahwa nilai CA \& CR seluruh variabel laten memenuhi kriteria, yakni di atas 0,7. Nilai CA untuk masing-masing variabel Lingkungan Kerja $\left(\mathrm{X}_{1}\right)$, Kompensasi $\left(\mathrm{X}_{2}\right)$, Religiusitas $\left(\mathrm{X}_{3}\right)$ dan Keinginan Pegawai untuk Berhenti Bekerja (Y) adalah : 0,893, 0,942, 0,933 dan 0,914. Adapun nilai CR masing-masing variabel di atas berturut-turut adalah : 0,913, 0,953, 0,938, dan 0,940. Flynn et al. (1994) menyatakan bahwa nilai Cronbach's Alpha >0,7 berarti indikator yang digunakan dapat diterima karena nilai alphanya kuat.

Adapun untuk nilai AVE, seluruh variabel memenuhi ketentuan ambang batas $(>0,5)$. Nilai AVE masing-masing variabel Lingkungan Kerja $\left(\mathrm{X}_{1}\right)$, Kompensasi $\left(\mathrm{X}_{2}\right)$, Religiusitas $\left(\mathrm{X}_{3}\right)$ dan 
Keinginan Pegawai untuk Berhenti Bekerja (Y) adalah : 0,513, 0,744, 0,507, dan 0,795. Menurut Hair et al. (2014), nilai AVE > 0,5 adalah cukup baik.
Kemudian, penelitian ini akan menguji hubungan antara lingkungan kerja, kompensasi dan religiusitas terhadap keinginan pegawai untuk berhenti bekerja. Berikut adalah hasilnya:

\section{Pengujian Hipotesis}

Tabel 10

Analisis Nilai T-Statistik

\begin{tabular}{|c|c|c|c|c|c|}
\hline T-Statistics Test & $\begin{array}{c}\text { Original } \\
\text { Sample }(\mathrm{O})\end{array}$ & $\begin{array}{c}\text { Sample } \\
\text { Mean (M) }\end{array}$ & $\begin{array}{l}\text { Standard } \\
\text { Error } \\
\text { (STERR) }\end{array}$ & $\begin{array}{l}\text { T-Statistics } \\
\text { (O/STERR) }\end{array}$ & $\begin{array}{c}\mathrm{P} \\
\text { Values }\end{array}$ \\
\hline $\begin{array}{l}\text { Lingkungan } \\
\text { Kerja -> } \\
\text { Keinginan } \\
\text { pegawai untuk } \\
\text { berhenti bekerja }\end{array}$ & $-0,296$ & $-0,304$ & 0,081 & $-3,667$ & 0,000 \\
\hline $\begin{array}{l}\text { Kompensasi -> } \\
\text { Keinginan } \\
\text { pegawai untuk } \\
\text { berhenti bekerja }\end{array}$ & $-0,308$ & $-0,305$ & 0,085 & $-3,607$ & 0,000 \\
\hline $\begin{array}{l}\text { Religiusias -> } \\
\text { Keinginan } \\
\text { pegawai untuk } \\
\text { berhenti bekerja }\end{array}$ & 0,078 & 0,078 & 0,058 & 1,331 & 0,184 \\
\hline
\end{tabular}

Dilihat dari kolom Original Sample, hubungan lingkungan kerja dengan keinginan pegawai untuk berhenti bekerja bernilai negatif, ini menunjukkan lingkungan kerja mempengaruhi keinginan pegawai untuk berhenti bekerja secara negatif. Kemudian hubungan kompensasi dengan keinginan pegawai untuk berhenti bekerja bernilai negatif, ini menunjukkan kompensasi mempengaruhi keinginan pegawai untuk berhenti bekerja secara negatif pula. Sementara, hubungan religiusitas dengan keinginan pegawai untuk berhenti bekerja bernilai memiliki nilai positif, sehingga dapat diartikan religiusitas mempengaruhi keinginan pegawai untuk berhenti bekerja secara positif.

\section{Pembahasan}

Hasil analisa tabel 10, dapat dilihat dari nilai t-statistik, hubungan lingkungan kerja dengan keinginan pegawai untuk berhenti bekerja adalah negatif, dengan nilai $\mathrm{t}$-statistik $=-3,667$. Ini berarti adanya lingkungan kerja yang baik membuat keinginan pegawai untuk berhenti bekerja menjadi berkurang. Semakin baik lingkungan kerjanya, semakin kecil pula keinginan pegawai untuk berhenti bekerja dari perusahaan tersebut.

Hal ini sesuai dengan apa yang disimpulkan oleh Earle (2003), Mayfield dan Mayfield (2007) dan Applebaum et al. (2010). Lingkungan kerja yang buruk akan cenderung membuat pegawai kehilangan fokusnya dalam bekerja. Hubungan kerja yang baik dengan rekan kerja juga turut mencegah seorang pegawai untuk berhenti bekerja (Madden et al., 2015).

Selanjutnya, hubungan kompensasi dengan keinginan pegawai untuk berhenti bekerja adalah negatif, dengan nilai $t$-statistik $=-3,607$. Ini berarti kompensasi yang berada pada tingkat yang memuaskan bagi pegawai akan membuat keinginan pegawai untuk berhenti bekerja menjadi berkurang. Semakin memuaskan kompensasi yang diterima pegawai, semakin kecil pula keinginan pegawai untuk berhenti bekerja dari perusahaan tersebut. Hal ini sejalan dengan hasil penelitian Liu (2012) dan Delery et al. (2000). Jung dan Yoon (2015) juga mengemukakan bahwa kepuasan terhadap kompensasi yang diterima akan memberikan efek psikologis yang positif bagi pegawai dan mencegahnya keluar dari perusahaan.

Berlawanan dengan lingkungan kerja dan kompensasi, hubungan religiusitas dengan keinginan pegawai untuk berhenti bekerja adalah positif, dengan nilai t-statistik $=1,331$. Hasil ini menandakan bahwa semakin tinggi tingkat religiusitas seorang pegawai, akan mengakibatkan makin tingginya keinginan yang bersangkutan untuk berhenti bekerja dari perbankan syariah di Indonesia. 
Hal ini juga merupakan kesimpulan yang didapatkan Zafar et al. (2012) dalam penelitiannya. Namun, berbeda dengan penelitian ini, penelitian tersebut dilakukan terhadap pegawai di perbankan konvensional. Kemudian penelitian ini juga beririsan dengan penelitian Olowookere et al. (2016) yang menyatakan bahwa religiusitas intrinsik berpengaruh secara negatif terhadap keinginan pegawai untuk berhenti bekerja, namun religiusitas ekstrinsik berpengaruh secara positif terhadap keinginan pegawai untuk berhenti bekerja.

Hasil ini kemungkinan besar disebabkan oleh adanya sebagian pegawai perbankan syariah yang menganggap praktek transaksi keuangan di perbankan syariah belum sesuai syariah, minimal belum 100\% syariah (Masyarakat Tanpa Riba, 2019). Akibatnya para pegawai tersebut yang mayoritasnya adalah pegawai yang religius, merasa tidak nyaman untuk terus bertahan (bekerja) di bank syariah dan tidak sedikit yang memilih untuk resign. Alasan tersebut senada dengan yang diungkapkan oleh salah seorang mantan pegawai bank syariah melalui hasil wawancara dengan yang bersangkutan. Ini adalah tugas bersama sekaligus peluang bagi para stakeholder perbankan syariah untuk mengambil langkah-langkah menuju perbankan syariah yang benar-benar murni syariah.

\section{Simpulan}

Kesimpulan yang dapat diutarakan dalam penelitian ini setelah melalui proses pembahasan di atas, adalah bahwa lingkungan kerja dan kompensasi memiliki pengaruh negatif terhadap keinginan pegawai untuk berpindah kerja. Berarti semakin baik lingkungan kerja dan kompensasi di tempat kerja, akan membuat pegawai bank syariah menjadi enggan berpindah / berhenti bekerja dari perusahaannya sekarang. Berlainan dengan ketiga faktor tersebut, religiusitas memiliki pengaruh positif terhadap keinginan pegawai untuk berpindah kerja, yang berarti semakin religius seseorang, akan membuat keinginannya untuk berhenti bekerja (resign) dari perbankan syariah semakin tinggi.

\section{Keterbatas an Penelitian}

Penelitian ini tentunya belum sempurna dan memiliki banyak keterbatasan yang apabila dapat diperbaiki kedepannya, akan didapatkan hasil yang lebih baik. Di antara keterbatasan tersebut adalah:

1. Penelitian ini hanya mengambil sampel pegawai dari perbankan syariah, tanpa melakukan komparasi dengan pegawai perbankan konvensional di Indonesia.
2. Jumlah sampel di penelitian ini terbatas (209 orang).

3. Variabel independen yang diteliti dalam penelitian ini hanya tiga, yaitu lingkungan kerja, kompensasi dan religiusitas.

4. Entitas perbankan syariah yang ada dalam penelitian ini baru mencakup sekitar 50\% dari entitas perbankan syariah yang ada di Indonesia

\section{Saran}

Saran yang dapat disampaikan dari penelitian ini, adalah:

1. Perlu dilakukan penelitian lanjutan (future research) mengenai kepuasan kerja dan/atau keinginan pegawai untuk berhenti bekerja dengan menambahkan variabel independen lain, mengingat masih sangat banyak kemungkinan variabel independen yang dapat diteliti pengaruhnya terhadap variabel keinginan pegawai untuk berpindah kerja. Misalnya, kepemimpinan, hubungan atasan-bawahan, budaya organisasi, jam kerja fleksibel, kejelasan peran dalam pekerjaan, dan lain-lain.

2. Dapat dilakukan pula future research / confirmatory research dengan tema yang sama, di institusi / industri / negara / daerah yang berbeda, untuk memastikan universalitas hasil penelitian ini. Misalnya penelitian tentang keinginan pegawai untuk berhenti bekerja di industri asuransi syariah atau koperasi syariah. Bisa juga meneliti mengenai keinginan pegawai untuk berhenti bekerja di provinsi tertentu, atau di negara-negara tetangga.

3. Perlu dilakukan future research / confirmatory research mengenai penyebab faktor religiusitas dapat secara positif mempengaruhi keinginan pegawai untuk berhenti bekerja.

4. Perlu dilakukan penyusunan dan perumusan akad-akad di perbankan syariah agar benarbenar murni syariah, yang melibatkan seluruh stakeholder, diantaranya 'ulama / pemuka agama, pemerintah, dan perwakilan pihak bank syariah.

\section{Daftar Pustaka}

Abbasi, S. M., \& Hollman, K. W. (2000). Turnover: The Real Bottom Line. Public Personnel Management, 29(3), 333-342.

Abu-Raiya, H., Pargament, K. I., Mahoney, A., \& Stein, C. H. (2008). A Psychological Measure of Islamic Religiousness: Development and Evidence for Relevance, Reliability and Validity. International Journal for the Psychology of Religion, 
$18(4)$,

291-315.

$10.1080 / 10508610802229270$.

Al-Hummadi, B. A. (2013). Leadership, Employee Satisfaction and Turnover in The UAE Public Sector (Doctoral Dissertation). The British University in Dubai.

Applebaum, D., Fowler, S., Fiedler, N., Osinubi, O., \& Robson, M. (2010). The Impact of Environmental Factors on Nursing Stress, Job Satisfaction, and Turnover Intention. The Journal of Nursing Administration, 40, 323-328.

Altman, Y. (2009). From Human Resources to Human Beings: Managing People at Work. Human Resource Management International Digest, 17(7), 3-4.

Becker, B., \& Gerhart, B. (1996). The Impact of Human Resource Management on Organizational Performance : Progress and Prospects. Academy of Management Journal, 39(4), 779-801.

Delery, J. E., Gupta, N., Shaw, J. D., Jenkins, G. D., \& Ganster, M. L. (2000). Unionization, Compensation, and Voice Effects on Quits and Retention. Industrial Relation, 39(4), 625-645.

Earle, H. A. (2003). Building A Workplace of Choice: Using The Work Environment to Attract and Retain Top Talent. Journal of Facilities Management, 2(3), 244-257.

Flynn, B. B., Schroeder, R. G., \& Sakakibara, S. (1994). A Framework for Quality Management Research and An Associated Measurement Instrument. Journal of Operations Management, 11, 339-366.

Hair, J. F., Black, W. C., Babin, B. J., \& Aderson, R. E. (2014). Multivariate Data Analysis $7^{\text {th }}$ ed. Harlow, United Kingdom: Pearson.

Jung, H. S., \& Yoon, H. Y. (2015). Understanding Pay Satisfaction: The Impacts of Pay Satisfaction on Employees' Job Engagement and Withdrawal in Deluxe Hotel. International Journal of Hospitality Management, 48, 22-26. i: Lee, T. W., \& Mowday, R. T. (1987). Voluntarily Leaving An Organization: An Empirical Investigation of Steers and Mowday's Model of Turnover. Academy of Management Journal, 30(4), 721-743.

Liu, S. (2012). The Influences of School Climate and Teacher Compensation on Teachers' Turnover Intention in China. Educational Psychology: An International Journal of Experimental Educational Psychology, 32(5), 553-569.

Madden, L., Mathias, B. D., \& Madden, T. M. (2015). In Good Company: The Impact of Perceived Organizational Support and Positive Relationships at Work on Turnover Intentions. Management Research Review, 38(3), 242-263.

Masyarakat Tanpa Riba. (2019). KesalahanKesalahan Fatal Pengusaha Mengembangkan Bisnis dengan Utang Revisi ke-10. Depok: Masyarakat Tanpa Riba.

Mayfield, J., \& Mayfield, M. (2008). The Creative Environment's Influence on Intent to Turnover. Management Research News, 31(1), 41-56.

Misra, P., Jain, S., \& Sood, A. (2013). Compensation: Impact of Rewards and Organisational Justice on Turnover Intentions and The Role of Motivation and Job Satisfaction: A Study of Retail Store Operations in NCR. International Journal of Human Resources Development and Management, 13(2-3), 136-152.

Olowookere, E. I., Adekeye, O. A., Adejumo, G. O., Agoha, B. C., \& Sholarin, M. A. (2016). Influence of Religiosity on Turnover Intention: Empirical Evidence from Selected Employees in Lagos and Ogun States. IFE Psychologia: An International Journal, 24(2), 132-138.

Punia, B. K., \& Sharma, P. (2008). Employees' Perspective On Human Resource Procurement Practices As A Retention Tool in Indian IT Sector. The Journal of Business Perspective, 12(4), 57-69. 
Ramlan, S. F. (2017). Refining The Theoretical Construct of Islamic Work Ethic: A Qualitative Study (Doctoral Dissertation). University of Malaya.

Raziq, A., \& Maulabakhsh, R. (2015). Impact of Working Environment on Job Satisfaction. Procedia Economics and Finance, 23, 717725.

Samuel, M. O., \& Chipunza, C. (2009). Employee Retention and Turnover: Using Motivational Variables as A Panacea. African Journal of Business Management. 3(8), 410-415.

Suliman, A. M., \& Al-Obaidli, H. (2011). Organizational Climate and Turnover in Islamic Banking in The UAE. International Journal of Islamic and Middle Eastern Finance and Management, 4(4), 308-324.

Zafar, R., Altaf, M., Bagram, M. M. M., Hussain, H., Tabassum Riaz, A. H., Nadim, M., \& Chaudhry, M. S. (2012). Religiosity, as Determinant of Turnover Intention: An Exploratory Study. The Journal of Commerce, 4(4), 1-8. 